J. Dairy Sci. 94:6257-6258

doi:10.3168/jds.2011-94-12-6257

(C) American Dairy Science Association ${ }^{\circledR}, 2011$.

\title{
Erratum to "Effect of moderate pressure treatments on microstructure, texture, and sensory properties of stirred-curd Cheddar shreds" (J. Dairy Sci. 87:3172-3182)
}

\section{J. Serrano, G. Velazquez, K. Lopetcharat, J. A. Ramirez, and J. A. Torres}

A diligent reader identified duplication between Serrano et al. (2004) and Serrano et al. (2005). Inadvertently, 3 figures were identical between these manuscripts.

The following 3 figures (Figures 2, 3, and 4) are the correct figures for the results on stirred-curd Cheddar and should replace the figures originally published in Serrano et al. (2004) that corresponded to milled-curd Cheddar.

The authors regret the error.

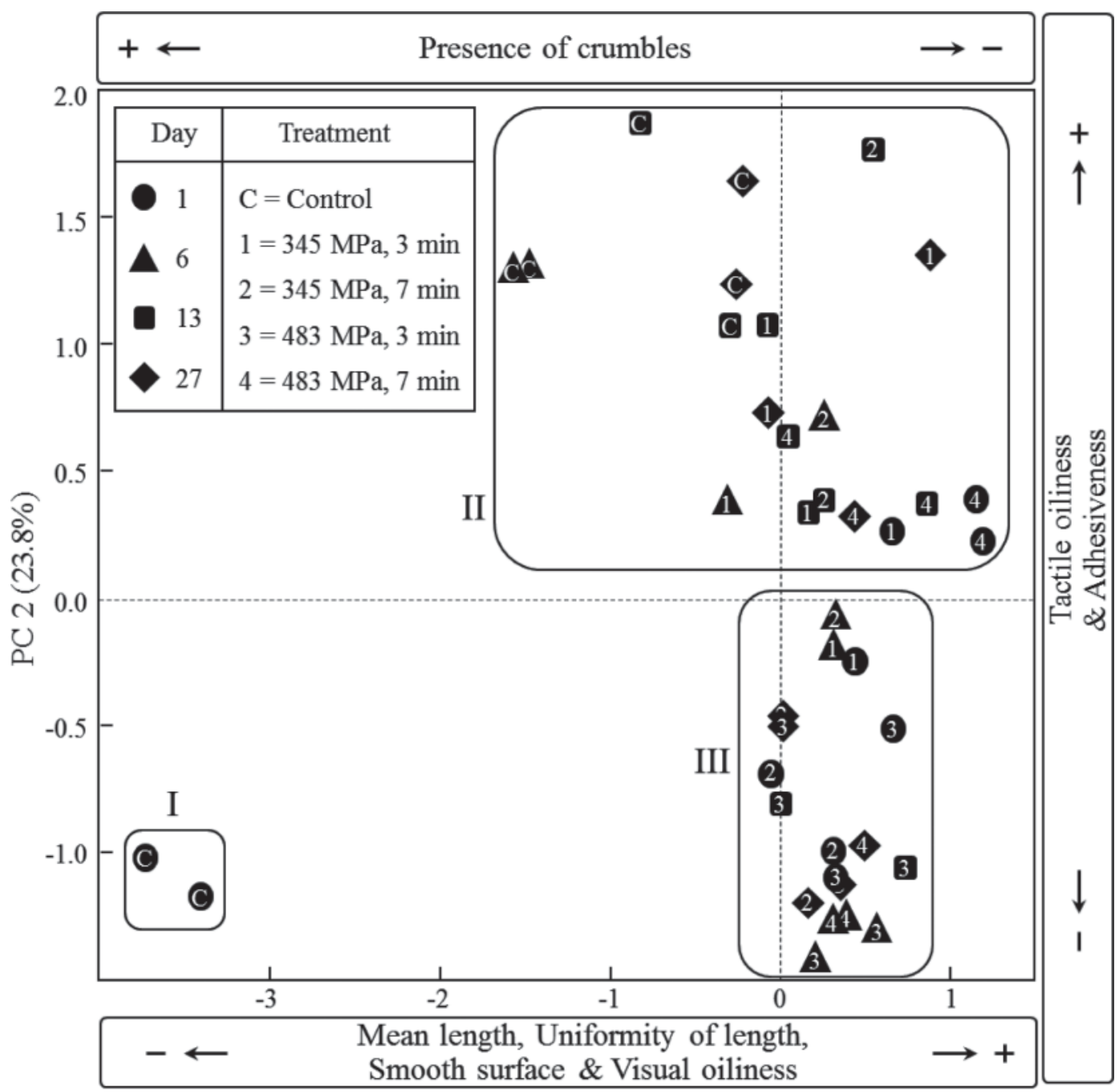

PC $1(52.4 \%)$

Figure 2. Principal component (PC) analysis for the pressure effect on the sensory properties of stirred curd Cheddar cheese. 

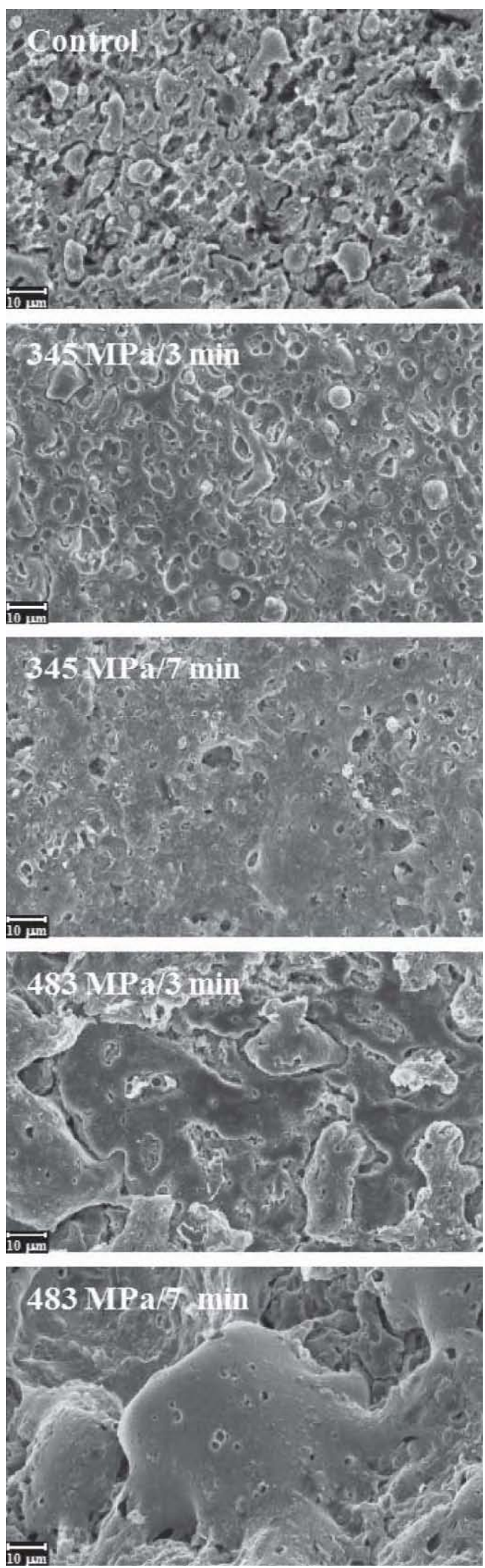

Figure 3. Scanning electron microscopy micrographs of pressuretreated and control stirred-curd Cheddar cheese $(1,000 \times$ magnification, bar $=10 \mu \mathrm{m}$ )

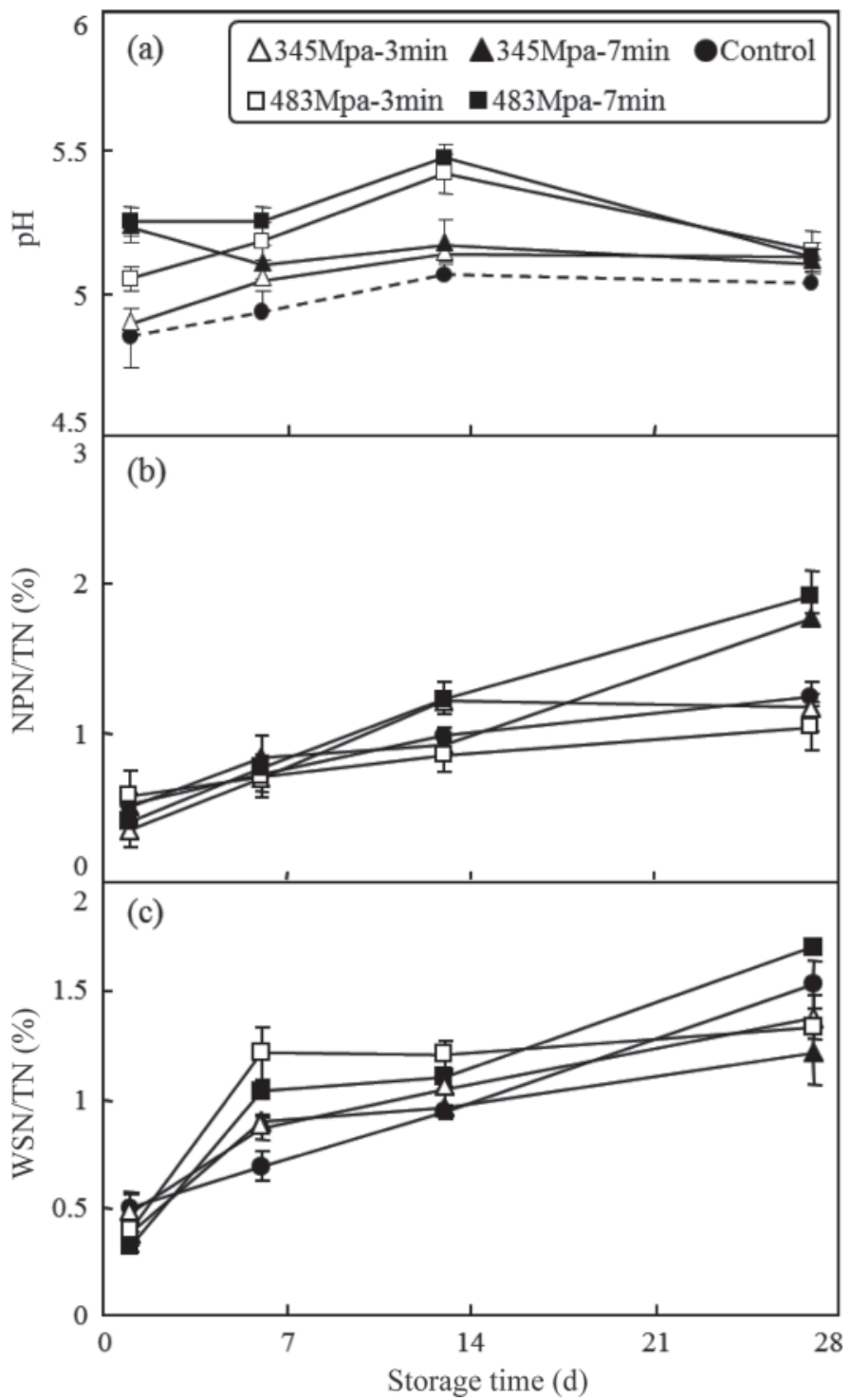

Figure 4. Effects of pressure treatment and ripening time on (a) $\mathrm{pH}$, (b) NPN as a percentage of total $\mathrm{N}(\mathrm{NPN} / \mathrm{TN})$, and (c) watersoluble nitrogen as a percentage of total $\mathrm{N}$ (WSN/TN) during ripening of stirred-curd Cheddar cheese.

\section{REFERENCES}

Serrano, J., G. Velazquez, K. Lopetcharat, J. A. Ramirez, and J. A. Torres. 2004. Effect of moderate pressure treatments on microstructure, texture, and sensory properties of stirred-curd Cheddar shreds. J. Dairy Sci. 87(10):3172-3182.

Serrano, J., G. Velazquez, K. Lopetcharat, J. A. Ramirez, and J. A. Torres. 2005. Moderately high hydrostatic pressure processing to reduce production costs of shredded cheese: Microstructure, texture, and sensory properties of shredded milled curd Cheddar. J. Food Sci. 70:S286-S293. 